\title{
FIFTIETH VOLUME OF HETEROCYCLES: PREFACE
}

Our Journal has reached another milestone with its Fittleth Volume. As we all know, in addition to the regular yearly volumes, issued monthly, Heterocycles initiated in 1976 a series of special volumes to mark important anniversaries and to pay appropriate tributes to chemists who had made significant contributions to the subject.

We need as heterocyclic chemists, to hold our heads high. Society cannot operate efficiently without us. All the impressive advances of blological chemistry, genetic manipulation, enzymatic transformation, antibody recognition, depend on the basic principles of Heterocyclic Chemistry. It is scandalous that in many great universities, chemists can graduate without more than the skimpiest knowledge of heterocyclic chemistry. It is commonplace to hear that on recruitment of organic chemists into pharmaceutical and biotechnological companies, a first necessity for the new recruit, is to familianize him/herself, with some basic heterocyclic chemistry concepts.

Heterocycles are of vital importance in the race to improve our understanding of the basic chemistry which underlies nearly all of the important life-processes and a large proportion of transformations leading to and creating the increasingly sophisticated products, which enhance our society today and hopefully will long continue to do so.

On behalf of the readers of Heterocycles, 1 would like to dedicate this fiftieth celebration volume to all of those who have enabled and who continue to enable the publication of our journal. We salute our authors, noting their international character from all of the continents and so many countries, who have taken advantage of the excellent facilities and efficient operation of our journal. We thank our Senior Editorial Advisors and the whole Editorial Board for their support. We are grateful for the foresight of our founders and especially for the vision Tetsuji Kametani who, back in the early 1970's, foresaw the need for Heterocycles. Above all we dedicate the Fiftleth Volume of Heterocycles to our faithful staff who have worked so hard and with such loyalty under the exemplary leadership of our editor Keiichiro Fukumoto.

It is with great pleasure that I commend to you our readers this Fiftieth Volume in the confident expectation that wo will all find much to inspire us within its pages.

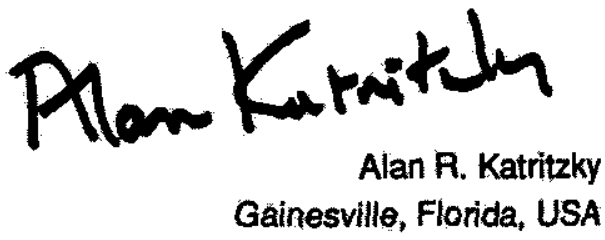

